\title{
Investigating Chinese EFL Learners' Comprehension of English Idioms
}

\author{
Hua Xie \\ School of Foreign Languages, Shanghai University of Electric Power, Shanghai, China
}

\begin{abstract}
This study investigates how Chinese EFL learners' understanding of English idioms is associated with their judgments of idiom familiarity, transparency. Another factor, context is also explored for its role in idiom comprehension. Results show learners' familiarity rating is positively correlated with their idiomatic knowledge, transparency rating does not indicate clear correlation; it is easier for learners to understand high-familiar and high-transparent idioms. Context exerts a facilitating role in learners' interpretation of idioms, and there are significant interaction effects between familiarity and context. The findings provide pedagogical implications for teachers to use classroom activities or exercises to increase learners' exposure to English idioms.
\end{abstract}

Index Terms-idiom familiarity, idiom transparency, context, idiom comprehension

\section{INTRODUCTION}

English is replete with idioms and other types of figurative language, such as metaphors, similes and irony. These types of figurative or nonliteral language enrich and enliven human communication. Idioms are groups of words that take on new, or figurative semantic meaning (Makkai, Boatner \& Gates, 1995). Idiomatic expressions are difficult to master because their meanings cannot be determined through a literal analysis of the individual word meanings. For instance, the figurative meanings of the idiom "to kick the bucket" (to die) can not be predicted through its constituent words "kick, the, bucket". Cooper (1999) pointed out idioms pose particular difficulties for virtually all groups of learners because the figurative meanings were unpredictable.

However, idiomatic expressions occur frequently in daily spoken and written communication. Pollie et al. (1977) found idiomatic expressions arose every 3 to 4 minutes in conversation. Milosky (1994) reported the frequent use of nonliteral expressions in social contexts (e.g., occurring 10 times per min of conversation) and in mass media outlets (e.g., 38 figurative uses on a single page of a teen magazine). Lazar et al. (1989) found at the kindergarten level (ages 5-6 years), approximately 5\% of teachers' classroom utterances directed to students contained at least one idiom, increasing to $20 \%$ by Grade 8 (ages 13-14years). In examining students' literature books, Nippold (1990) also reported at Grade 3 (ages 8-9 years), an average of $6 \%$ of sentences contained at least one idiom, increasing to $10 \%$ at Grade 8 . Levorato and Cacciari (1992) reported that mass media, textbooks and everyday language were rich with idiomatic expressions. As for foreign language learners, Nippold \& Martin (1989) stressed failure to grasp the meanings of idioms can impinge upon people's understanding of language in social, academic and vocative settings. Qualls \& Harris (1999) also asserted that the ability to understand idioms is important for successful communication. Therefore, it is necessary for learners to know how to interpret nonliteral figurative meanings of idiomatic expressions for effective communication. Otherwise, there is potential for communication breakdown during verbal and written interactions.

The majority of research has been conducted on native English speakers' comprehension of idioms, especially children and adolescents. Previous work has widely examined variables that may influence the comprehension of English idiomatic expressions. Among them, three factors have been focused on, namely, familiarity, transparency, and context. However, limited empirical studies have investigated the role of these three factors in Chinese EFL learners' comprehension of idioms. This study intends to fill this gap concerning Chinese EFL learners' idiom comprehension under the influence of these factors.

\section{FACTORS AFFECTING IDIOM COMPREHENSION}

\section{Familiarity and transparency of idioms}

Idiom familiarity is a measure of how frequently an idiom occurs in the language (Nippold \& Taylor, 1993). For example, a piece of cake is an idiom that often occurs in English, but to talk through one's hat is one that rarely occurs. Familiarity effects have been interpreted within a "language experience" hypothesis of figurative development, which claims that development of figurative language depends on the amount of meaningful exposure one has to nonliteral expressions (Nippold \& Taylor, 2002). This hypothesis means idioms which occur more often are probably learned earlier.

Transparency is a measure of the degree to which the literal and figurative meanings of an idiom are related. When the literal and figurative meanings are related closely, idioms are regarded transparent, but when the two types of 
meanings are unrelated, idioms are regarded as opaque. For example, the figurative meaning of the idiom to get away with murder (to escape punishment for something serious) can be easily derived from the literal interpretation of the constituent words, whereas the figurative meaning of to keep one's shirt on (to remain calm and not overreact) can not be inferred from the individual words in the phrase.

Some researchers have studied the role of familiarity and transparency in English idiom comprehension for native children and adolescents. Levorato \& Cacciari (1992) examined 7-year and 9-year old children's comprehension of idioms and their judgments of idiom familiarity and found it was easier for children to understand high-familiar idiom. Nippold \& Rudzinski (1993), Nippold \& Taylor (1995) investigated the effects of familiarity and transparency on different age groups of children's understanding of idioms. The results showed there was significant correlation between the children's judgments of familiarity, transparency and their comprehension of idioms no matter what age group they were in. High-familiar and high-transparent idioms were easier to be understood. Later, Nippold \& Taylor (2002) found children's accurate understanding of idioms increased as age developed, younger children had lower judgments of idiom familiarity, but there was no significant difference between the judgments of transparency for different age groups of children. In a cross-cultural study, Qualls \& Harris (1999) investigated the effect of familiarity on idiom comprehension of African American and European American fifth graders, and found the two groups performed differently in understanding idioms with low familiarity, whereas had similar performance in understanding idioms with moderate and high familiarity.

Recently a few studies have focused on the way how EFL/ESL learners comprehend English idioms. Sameer (2013) compared two groups of college students' judgments of familiarity and transparency and their comprehension of English idioms in Saudi Arabia, and the results showed Level 4 students rated the idioms higher in familiarity and comprehended them more accurately than L1 students did. However, the two groups performed similarly on the idiom transparency task. Majuri (2014) investigated the effect of frequency and transparency on Finnish and Italian students' recognition of the meanings of English idioms. The finding showed frequency did not seem to have a large effect on the learners while transparency was of assistance. Tiv (2016) studied how transparency and ambiguity affected learning of unfamiliar idioms. The results showed when only these two properties were used to predict learners' accuracy of idiom comprehension, transparency has a robustly significant effect on learning.

Context and idiom comprehension

There is a considerable body of research on the probable effect context exerts on understanding and interpreting L1 idioms (Ackerman, 1982; Cacciari \& Levorato, 1989; Gibbs, 1987, 1995; Levorato \& Cacciari, 1992; Laval, 2003; Liontas, 2003; Nippold \& Martin, 1989; Qualls et al., 2003; Ortony, Schallert, Reynolds, et al., 1978). Ortony, Schallert, Reynolds, and Antos (1978) examined the effects of either short or long contexts on metaphorical and idiomatic phrases or literal phrases interpretation, and found the subjects spent longer time understanding metaphorical phrases than literal phrases in the short context condition. Ackerman (1982) investigated the role of contextual information and the conventional forms of idioms in children's comprehension of idioms. The results revealed that 6-year and 8-year-olds could correctly understand the sentences in idiomatic contexts, whereas the 10-year-olds and the adults could understand the sentences not only in idiomatic contexts but also in literal and neutral contexts. This suggested that younger children needed idiomatically biasing contexts more than older children to figure out the real meanings of idioms. In Nippold \& Martin's (1989) study, adolescents at age 14 to 17 were asked to interpret idioms presented with and without contextual information. The results demonstrated that linguistic contextual information did enhance adolescents' interpretation of idioms, and the accuracy of understanding improved as the age increased, no matter whether the context was presented or not. Liontas (2003) explored the effect of context on adult Spanish learners' idiom comprehension and also found context was a big help in the construction of the idiomatic meanings.

Concerning the effect of context on EFL/ESL learners' idiom comprehension, some studies have provided support for the similar view that facilitating roles do occur. Norton (1979) found the existence of context was helpful for learners to understand idiomatic expressions in narrative passages. Atai \& Akbarian (2003) also proved different contexts had significant effects on EFL learners' acquisition of idioms. Research on EFL idiom processing strategies has also proved context plays an important role in idiom comprehension. Cooper (1999) investigated the on-line processing strategies used by ESL learners who were asked to state out the meanings of selected idioms presented with a written context and found guessing from context was most frequently used among the variety of strategies adopted. Bulut et al's study on Turkish teachers of English also found in their idiom interpretation, the contextual clues were used more often than any other clue (Bulut \& Çelik-Yazici, 2004). Rohani et al (2012) investigated the effect of context on the strategies Iranian EFL learners utilized to process idioms and concluded that creating the appropriate context would prove productive in enhancing the language learning process.

From the aforementioned review, we can see the related empirical studies have mainly investigated the effects of familiarity, transparency and context on idiom comprehension by native speakers, whereas limited empirical studies have been carried out to explore the roles of these factors on Chinese EFL learners' idiom understanding. This study is an attempt, intending to address three questions:

1. What is the relationship between familiarity, transparency and idiom comprehension for Chinese EFL learners?

2. What effect does context exert on Chinese EFL learners' understanding of English idioms?

3. Is there any interaction effect among idiom familiarity, transparency and context on Chinese EFL learners' 
comprehension of English idioms?

\section{RESEARCH METHOD}

\section{Subjects}

A total of 70 sophomore students in two natural classes from a key university in Shanghai participated in this research. They had no previous experience of participation in any kind of exercises or tests on English idioms. All of them voluntarily took part in the experiments.

\section{Materials}

\section{Idiom Comprehension Task (ICT)}

This task consisted of 20 English idioms selected from published research and reference books of idioms (Gibbs, 1995; Makkai et al., 1995; Nippold \& Rudzinski, 1993; Nippold \& Taylor, 1995, 2002; Qualls \& Harris, 1999, 2003). These particular idioms were selected because previous research had shown they represented a wide range of familiarity and transparency levels. To address the effect of context on idiom comprehension, two versions of the ICT (in isolation and in context) were constructed for this study. In the first condition the 20 idioms were listed without contextual information. The subjects were asked to write down their own understanding of these idioms in English or in Chinese. In the second condition, each idiom was presented with a brief narrative context. In the final sentence, a question concerning what the idiom meant was posted. Under these two conditions, the subjects got one score if they wrote down the correct meaning of each idiom. The score range was 0 to 20 .

\section{Familiarity Judgmental Task}

In this task, the set of 20 idioms randomly ordered were given on a booklet. The participants were asked to indicate how often they had heard or read each idiom before, using a 3-point scale and circle the number and associated descriptive term (e.g. $2=$ several times) with which they most agreed. Finishing this task, the subjects got the score range of 20 to 60. An example was as follows:

I have heard or read this idiom: let the cat out of the bag

$1=$ rarely $\quad 2=$ several times $\quad 3=$ many times

\section{Transparency Judgment Task}

Like the familiarity task, the participants were given a booklet containing the same set of 20 idioms. For each idiom, they were asked to indicate how closely they believed the literal and figurative meanings were related using a 3-point scale and circle the number and associated descriptive term (e.g. $2=$ somewhat related) with which they most agreed. The subjects got the score range from 20 to 60. An example was presented as follows:

To miss the boat:

Literal meaning: to miss the time to get aboard Figurative meaning: to lose a good chance

The meanings of this idiom are:

$1=$ not related $\quad 2=$ somewhat related $\quad 3=$ closely related

Before the tasks were administered, a pilot study was conducted with a group of 30 students who were not the subjects in the study to test the reliability, familiarity judgment task, $r=.73$; transparency judgment task, $r=.78$; idiom comprehension test (with context), $\mathrm{r}=$. 81; idiom comprehension test (without context), $\mathrm{r}=.76$, which proved the designed tests had high reliability.

\section{Procedure}

The participants from two natural classes were tested in their respective English class time. They were asked to perform the tasks in the following order: Familiarity Judgment Task, Idiom Comprehension Task (in isolation), Idiom Comprehension Task (in context), and Transparency Judgment Task. This particular sequence was adopted to obtain an unbiased estimate of participants' exposure to the tested idioms. The Idiom Comprehension Test, which asked the participants to write down their understanding of idioms in isolation and in context conditions, had to occur before the Transparency Task, which presented both the literal and figurative meanings of the idioms.

\section{Data analysis}

For the Familiarity and Transparency Judgment Tasks, the raw data of every idiom was taken down and the total scores of every participant were calculated. In the Idiom Comprehension Task (both in isolation and in context conditions), when the correct figurative meaning was presented, 1 score was given; if the wrong answer was put forth, 0 score was given. In the later analysis of the data, SPSS19.0 was adopted.

\section{Results}

\section{Familiarity, transparency and idiom comprehension}

Table 1 shows the overall performance of Chinese EFL learners in Familiarity Judgment Task, Transparency Judgment Task and Idiom Comprehension Task. As can be seen from this table, the mean raw score of students' familiarity judgment of the 20 idioms was only 32.40, a bit over the half of the total score (60). This indicates students' familiarity with the idioms was rather low, they have limited exposure to the idioms in their prior studying experience. On the transparency judgment, the mean score of 41.46 was found which proves the students tend to think there is always somewhat relationship between the literal meaning and figurative meaning of every idiom in their 
understanding.

TABLE 1.

MEAN RATINGS, SCORES, STANDARD DEVIATION AND RANGE

\begin{tabular}{lllll}
\hline & Mean & Std. Deviation & Min & Max \\
\hline Familiarity Judgment Task & 32.40 & 5.21 & 23.00 & 45.00 \\
Transparency Judgment Task & 41.46 & 6.86 & 26.00 & 54.00 \\
ICT (in isolation) & 6.21 & 1.78 & 2.00 & 10.00 \\
ICT (in context) & 12.31 & 2.52 & 5.00 & 18.00 \\
\hline
\end{tabular}

Table 2 shows the list of the 20 idioms in the order of increasing accuracy of students' performance on the Idiom Comprehension Task (with the contextual information). The mean familiarity rating and transparency rating are shown as well. To determine if idiom familiarity and transparency were associated with idiom comprehension, two types of correlation analyses were carried out. First, using the means for each idiom reported in Table 2, correlation coefficients were calculated for familiarity and comprehension, and for transparency and comprehension respectively. The results were statistically significant for familiarity judgment task and comprehension tasks under two conditions (comprehension in isolation: $\mathrm{r}=.732, p<0.05$; comprehension in context: $\mathrm{r}=.562, p<0.05$ ). However, the results were not statistically significant for transparency task and both conditions of comprehension (comprehension in isolation: $\mathrm{r}=.383$, $p>0.05$; comprehension in context: $\mathrm{r}=.352, p>0.05$ ). Second, correlation analyses were also performed using each subject's total raw scores in the familiarity, transparency, and comprehension tasks. The results were not statistically significant for familiarity and comprehension (comprehension in isolation: $\mathrm{r}=-.038, p>0.05$; comprehension in context: $\mathrm{r}=-.105, p>0.05$ ); for transparency and comprehension (comprehension in isolation: $\mathrm{r}=.08, p>0.05$; comprehension in context: $\mathrm{r}=.023, p>0.05$ ). These insignificant findings may reflect the relative homogeneity of this set of idioms, given the small standard deviations for each of the key properties reported in Table 2.

TABLE 2.

LIST OF IDIOMS WITH MEAN FAMILIARITY AND TRANSPARENCY RATINGS AND COMPREHENSION SCORES

\begin{tabular}{lllll}
\hline \multicolumn{1}{c}{ Idiom } & Familiarity & Transparency & ICT (in context) & ICT(in isolation) \\
\hline Let sleeping dogs lie & 1.39 & 2.09 & 0.19 & 0.19 \\
Turn the other cheek & 1.17 & 2.04 & 0.24 & 0.01 \\
Pull one's leg & 1.81 & 1.83 & 0.26 & 0.01 \\
Pain in the neck & 1.53 & 2.1 & 0.31 & 0.03 \\
Go into one's shell & 1.23 & 2.04 & 0.33 & 0.07 \\
Make a mountain out of a molehill & 1.3 & 2.11 & 0.37 & 0.19 \\
Face the music & 1.29 & 2.01 & 0.44 & 0.04 \\
Get away with murder & 1.33 & 2.19 & 0.53 & 0.36 \\
Be all ears & 1.53 & 2.1 & 0.56 & 0 \\
Talk through one's hat & 1.17 & 1.93 & 0.56 & 0.47 \\
Cry over spilled milk & 2.07 & 2.06 & 0.69 & 0.03 \\
See eye to eye & 1.91 & 1.9 & 0.77 & 0.93 \\
Skate on thin ice & 1.84 & 2.07 & 0.81 & 0.23 \\
Cold shoulder & 1.37 & 2.07 & 0.84 & 0.89 \\
A piece of cake & 2.66 & 2.21 & 0.87 & 0.37 \\
Miss the boat & 1.39 & 2.29 & 0.87 & 0.36 \\
Let the cat out of the bag & 1.71 & 2.17 & 0.87 & 0.39 \\
Keep someone at arm's length & 1.73 & 2.09 & 0.9 & 0.96 \\
Get in one ear and out the other & 2.2 & 2.09 & 0.94 & 0.7 \\
Be led by the nose & 1.8 & 2.07 & 0.96 & 0.31 \\
\hline Mean & 1.62 & 2.07 & 0.62 & 0.33 \\
Std. Deviation & 0.39 & 0.10 & 0.27 & $0-0.96$ \\
Range & $1.17-2.66$ & $1.83-2.29$ & $0.19-0.96$ & \\
\hline
\end{tabular}

To examine further the association between familiarity, transparency, and idiom comprehension, the five easiest and the five most difficult idioms were identified based on their mean comprehension score in the condition with contextual information. For each set of idioms - easiest and most difficult - each subject was assigned a raw score for the correctly comprehended idioms $(1 \times 5=5$ possible per set $)$ and the total score in rating the idioms familiarity $(3 \times 5=15$ possible per set) and transparency $(3 \times 5=15$ possible per set). The results are reported in Table 3 .

TABLE 3.

MEAN FAMILIARITY AND TRANSPARENCY RATINGS AND COMPREHENSION SCORES (IN CONTEXT) FOR THE FIVE EASIEST AND FIVE MOST DIFFICULT IDIOMS

\begin{tabular}{lllll}
\hline & & Mean & Std. Deviation & Std. Error Mean \\
\hline \multirow{2}{*}{ Familiarity } & Easiest & 10.10 & 1.88 & 0.22 \\
\cline { 2 - 5 } & Most difficult & 7.13 & 1.93 & 0.23 \\
\hline \multirow{2}{*}{ Transparency } & Easiest & 10.63 & 3.15 & 0.38 \\
\cline { 2 - 5 } & Most difficult & 10.10 & 1.99 & 0.24 \\
\hline \multirow{2}{*}{$\begin{array}{l}\text { (in context) } \\
\text { in }\end{array}$} & Easiest & 4.40 & 0.84 & 0.10 \\
\cline { 2 - 5 } & Most difficult & 1.10 & 0.95 & 0.11 \\
\hline
\end{tabular}

It can be seen that the mean familiarity ratings of the easiest and most difficult sets of idioms were 10.10 and 7.13, 
which indicates the easiest set of idioms were more familiar to the students. For the mean transparency ratings of the two sets of idioms, there was slight difference between 10.63 and 10.10. As for the means of comprehension scores of the easiest idioms and most difficult idioms, there was a big difference between 4.40 and 1.10. To test whether the differences on these three measures for the two sets of idioms were significant, Paired Samples Test was conducted. The results demonstrate that easiest idioms were significantly more familiar $(\mathrm{t}=10.825, p<0.05)$ than the most difficult ones. No significant difference was found on the transparency ratings of the two sets $(\mathrm{t}=1.237, p=.220)$. In addition, there was also significant difference between the easiest sets of idioms and the most difficult set of idioms concerning student's correct comprehension.

\section{Context and idiom comprehension}

Referring to Table 1, students' performance on idiom comprehension in both conditions were rather dissatisfying. In the condition with supportive context, the mean score of accuracy was 12.31 , the answering rate being $61.55 \%$; while in the isolation condition, the mean score of comprehension was much lower, 6.21, the answering rate being even lower, $31.05 \%$. Although the general picture was very gloomy, the facilitating role of context in idiom comprehension can be testified clearly. With the aid of supportive context, students' correct comprehension of idioms improved to a great extent.

To examine further how context facilitates the better understanding of idioms, Table 2 should be mentioned again. Comparing the mean comprehension score of every idiom in the isolation condition and in the context condition, we can see the mean accuracy score increased more or less for most idioms. Especially in students' correct understanding the figurative meanings of the idioms, see eye to eye, cold shoulder, let the cat out of the bag and keep someone at arm's length, their accuracy comprehension increased by over 50\%. For the idioms of talk through one's hat, pull one's leg, pain in the neck and turn the other cheek, in the isolation condition, students could hardly figure out the actual figurative meanings of theirs, only to give the literal translations of the constitute words. However, when these idioms were presented in the context, they could work out the figurative meanings more easily. Checking students' familiarity of these idioms, low exposure frequencies were found, which show these idioms are new and strange to them. However, with the support of contextual information, students' grasp of the figurative meanings of these idioms became better.

\section{Interaction effects between context and familiarity}

On account of no significant difference found in the transparency ratings of all idioms (mean rating range: 1.83-2.29) and no correlation existing between transparency and idiom comprehension, this factor will not be explored further in this part. However, the previous section has shown in understanding unfamiliar idioms, context facilitates students' correct comprehension of the figurative meanings of idioms. Therefore, the interaction effects of familiarity and context on idiom comprehension will be further analyzed.

Based on the mean familiarity ratings shown in Table 2, five most familiar and unfamiliar idioms were chosen as the high familiarity set and low familiarity set of idioms. Each subject's raw scores on these two sets of idioms in both conditions were summed and calculated, their mean scores and standard deviations were displayed in Table 4.

TABLE 4.

PERFORMANCE ON THE IDIOM COMPREHENSION TASK BY CONDITION AND FAMILIARITY

\begin{tabular}{l|l|l|l|l}
\hline & \multicolumn{2}{|l|}{ High familiarity } & \multicolumn{2}{l}{ Low familiarity } \\
\cline { 2 - 5 } & Mean score & Std. Deviation & Mean score & Std. Deviation \\
\hline ICT (in isolation) & 3.27 & 0.82 & 0.30 & 0.49 \\
\hline ICT (in context) & 4.09 & 0.90 & 1.94 & 1.26 \\
\hline
\end{tabular}

Students' performance varied across conditions and familiarity levels. Results indicated significant differences by familiarity levels for students' comprehension of idioms in the isolation and context conditions. When no supportive context was available, students' mean score was 3.27 for high-familiar idioms comprehension, for low-familiar idioms the mean score was only 0.30 . With the aid of contextual information, students' correct comprehension became much better, with the mean score rising to 4.09 in understanding high-familiar idioms and 1.94 in understanding low-familiar idioms.

TABLE 5.

PAIRED SAMPLES TEST

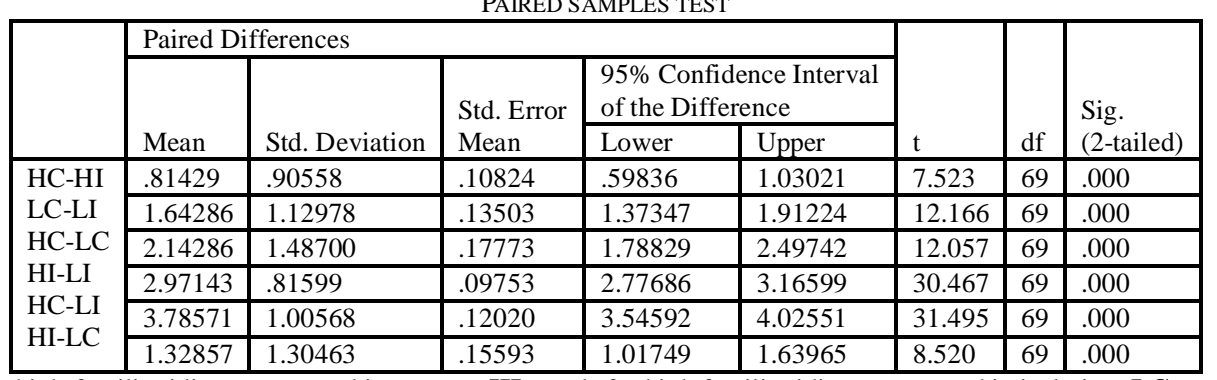

Note: HC stands for high-familiar idioms presented in context; HI stands for high familiar idioms presented in isolation; LC stands for low-familiar idioms presented in context; LI stands for low familiar idioms presented in isolation) 
A series of Paired Samples Tests was conducted to prove whether the differences were statistically significant (see Table 5). It was found that in both conditions of idiom comprehension, the students performed significantly better for the high-familiar idioms as compared to the low-familiar idioms (in the isolation condition: $\mathrm{t}=30.467, p<0.001$; in the context condition: $\mathrm{t}=12.057, p<0.001)$. Moreover, both in their comprehension of high-familiar and low-familiar idioms, the students performed better in the context condition in comparison with the condition of isolation (High-familiar idioms: $\mathrm{t}=7.523, p<0.001$; Low-familiarity: $\mathrm{t}=12.116, p<0.001)$. There were also significant differences between students' correct interpretation of figurative meanings of the high-familiar idioms in the context condition and low-familiar idioms in the isolation condition $(\mathrm{t}=31.495, p<0.001)$, and between their understanding high-familiar idioms in the isolation condition and low-familiar idioms with the contextual information $(\mathrm{t}=8.520, p<0.05)$.

ANOVA was used to test the interaction effects of idiom presentation conditions and idiom familiarity level. "The scores of correct comprehension of idioms" was adopted as the dependent variable, familiarity and presentation conditions were used as the independent variables, Repeated Measures ANOVA were used. Figure 1 shows the mean answering rate by context and familiarity level. The analysis yielded a significant effect of context $(\mathrm{F}=128.013$, $\mathrm{p}<0.001)$, and idiom familiarity $(\mathrm{F}=554.579, \mathrm{p}<0.001)$, and significant interactions between context and idiom familiarity $(\mathrm{F}=14.556, p<0.001)$. From this figure, it can be seen clearly students performed best in understanding high-familiar idioms when the supportive context was available, they did worst in comprehending low-familiar idioms when no context was available. It also demonstrated that especially in students' comprehension of low-familiar idioms, context played a more important facilitating role as compared to their understanding of high-familiarity idioms (the answering rate rising by $32.8 \%$ ). Another important finding was the facilitating role of familiarity was stronger than that of context.

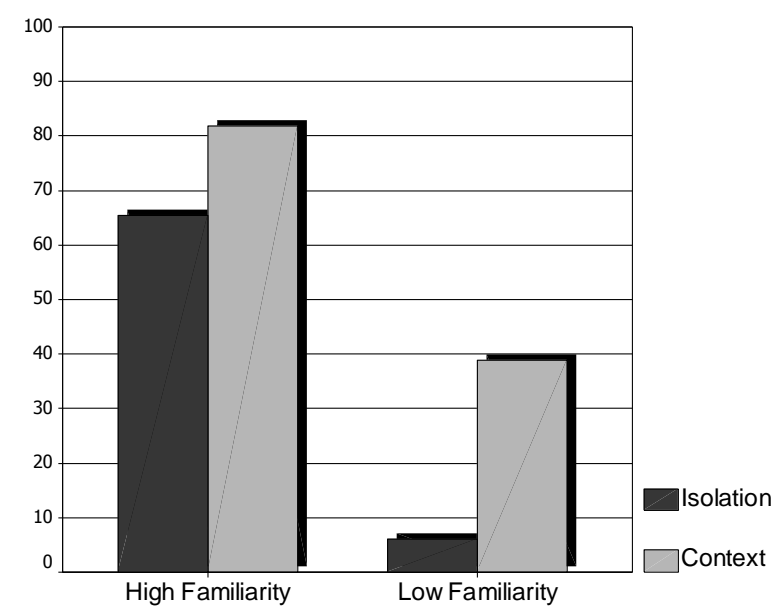

Figure 1. Mean idiomatic answering rate by context and familiarity level

To sum up, in both conditions of idiom comprehension, high-familiar idioms showed higher mean scores in comparison with low-familiar idioms. Moreover, regardless of familiarity level of idioms, students' performance in comprehending them was better with the help of contextual information as compared to their performance when no context was reachable.

\section{Discussion}

This study has investigated the roles of three factors in Chinese EFL learners' comprehension of idioms: idiom familiarity, idiom transparency, and context in the presentation of idioms.

Concerning the role of familiarity, based on students' own rating scale of the idioms, the results of low total score (32.40) indicated that Chinese students were not familiar with the idioms, and had a dissatisfying performance in comprehending the idioms correctly. This may be due to the drawbacks of English teaching in China. First, English idioms were not so stressed in Chinese English teaching classes. Teachers don't attach much importance to the teaching or explaining idioms. Therefore, in the learning process students do not spare any efforts to figure out what an idiom means when they are exposed to the idioms. Second, there are few systematic explanations and exercises on English idioms in textbooks or teaching materials. Teachers seldom use idioms in their oral presentation of lessons owing to their own limited idiomatic knowledge. In order for language acquisition to take place, the acquirer must receive comprehensible input through reading or hearing language structures that slightly exceed their current ability (Brown, 2000). Lacking sufficient input of idiom learning, learners are in adverse conditions to make improvements in idiom comprehension. Though students generally were less familiar with the tested idioms, they had better performance when high-familiar idioms were presented. This finding supports "language experience hypothesis" which was testified in developmental studies on native English speakers (Levorato \& Cacciari, 1992; Nippold \& Rudzinski, 1993; Nippold \& Taylor, 1995, 2002; Ortony et al., 1985). For Chinese EFL learners, the easiest idioms to understand are those much 
more familiar to them.

Previous developmental studies of younger English native speakers find it is easier for learners to do better when comprehending high-transparency idioms (Gibbs, 1987, 1991; Levorato \& Cacciari, 1999; Nippold \& Taylor, 1995, 2002). In other words, when the literal meaning and figurative meaning of an idiom is more closely related, the difficulty of accurate idiom comprehension will decrease. However, this study found no strong correlation between learners' ratings of idiom transparency and their performance in the idiom comprehension. The small range of transparency rating for each idiom (1.83-2.29) shows learners tend to have similar judgments of how closely the literal and nonliteral meanings of each expression are related. This result provides evidence to the suggestion that transparency is a relatively fixed property of idioms again (Nippold \& Taylor, 2002).

The findings regarding context are consistent with previous research on English native speaker and EFL/ESL learners as well (Atai \& Akbarian, 2003; Bulut \& Çelik-Yazici, 2004; Cacciari \& Levorato, 1989; Cooper, 1999; Gibbs, 1987; Nippold \& Martin, 1989; Qualls et al, 2003). Students' comprehension of idioms became better when the supportive context information was available compared to their performance when no context was presented. Qualls et al. (2003) proposes "proportionality theory" to explain idiom comprehension will decrease proportionally as the amount of context decreases. He compared rural English native adolescents' comprehension of idioms in three contexts: idioms in a story context, idioms in isolation, and idioms in verification task and found the story context yielded the greatest accuracy. In this study, the results indicate that "proportionality theory" is also applicable to Chinese EFL learners. Foreign language learners are able to increase their correct understanding of figurative meanings of idioms if the amount of context enlarges. Generally, idioms in a story context are explained more accurately than when they are presented in isolation. Context might facilitate the interpretation of figurative language by providing the necessary semantic information from which the reader (or listener) can extract or infer the appropriate sense of the expression. It may be more important for less common idioms whose meanings are not yet fully known, particularly for unfamiliar opaque idioms whose meanings are not fully derivable through semantic analysis of the phrases.

The results in the present study show familiarity and context not only play facilitating roles on their own, but also cause learners' accurate comprehension to increase when they are combined. When idioms were less familiar to them, contextual information enabled comprehension. And when the supportive context was not available, the frequency of prior meaningful exposure would influence learners' accurate responses. High-familiar idioms indicated greater accuracy. This finding suggests that EFL learners are able to overcome the boundary of unfamiliarity by using contextual cues or avail themselves of their former exposure amount to the idioms in the absence of contextual information. As a result, the two factors of familiarity and context may complement each other for learners to comprehend idioms well.

\section{CONCLUSION}

The present study investigated Chinese EFL learners' understanding of English idioms by revealing several variables' effects and their interactions, including familiarity, transparency and contextual factors. The findings provide supportive evidence that familiarity and context both contribute to Chinese learners' accurate comprehension of English idioms. If learners are very familiar with idioms, and in the presence of contextual information, it will be easier for them to guess or figure out the figurative meanings of idioms.

The results provide implications for English language researchers and teachers. To improve foreign language learners' idiomatic knowledge, increasing their exposure opportunities to idioms is highly important. Language researchers and teachers may consider inclusion of more idiomatic expressions in the compilation of textbooks or exercise books, teachers may create more activities, listening or speaking, to teach and explain more idioms, thus increasing their meaningful exposure amount to this kind of figurative language. In the class time, teachers should purposefully elaborate on the formation of idioms and their figurative meanings, and design some activities to provide meaningful contexts, thus giving learners better chances to understand idioms.

\section{REFERENCES}

[1] Ackerman, B.P. (1982). On comprehending idioms: Do children get the picture? Journal of Experimental Child Psychology, 33, 439-454.

[2] Atai, M.R.\& I. Akbarian. (2003). The effect of exposure on EFL learners' acquisition of idioms with reference to proficiency levels. Indian Journal of Applied Linguistics, 29/1, 21-34.

[3] Brown, H. Douglas. (2000). Principles of Language Learning and Teaching. Longman: New York 4th ed.

[4] Bulut, T. \& I. Çelik-Yazici. (2004). Idiom processing in L2: Through rose-colored glasses. The Reading Matrix, 4/2, $105-116$.

[5] Cacciari, C., \& Levorato, M. (1989). How children understand idioms in discourse. Journal of Child Language, 16, 387-405.

[6] Cooper, T. C. (1999). Processing of idioms by L2 learners of English. TESOL Quarterly, 33/ 2, 233-262.

[7] Gibbs, R. W. (1987). Linguistic factors in children's understanding of idioms. Journal of Child Language, 14, 569-586.

[8] Gibbs, R. W. (1991). Why many concepts are metaphorical. Cognition, 61/33, 309-319.

[9] Gibbs, R. W. (1995). The poetics of mind: Figurative thought, language, and understanding. Cambridge, U. K.: Cambridge University Press.

[10] Lavel, V. (2003). Idiom comprehension and metapragmatic knowledge in French children. Journal of Pragmatics, 35, 723-739.

[11] Lazar, R. T., Warr-Leeper, G. A., Nicholson, C. B., \& Johnson, S. (1989). Elementary school teachers' use of multiple meaning 
expressions. Language, Speech, and Hearing Services in Schools, 20, 420-430.

[12] Levorato, M. C., \& Cacciari, C. (1992). Children's comprehension and production of idioms: The role of context and familiarity. Journal of Child Language, 19/2, 415-433.

[13] Liontas, John I. (2003). Killing two birds with one stone: understanding Spanish VP idioms in and out of context. Hispania, $86 / 2,289-301$.

[14] Majuri, T. (2014). Idioms and L2 Learners: The Effect of L1, Transparency and Frequency on Idiom Comprehension by Finnish and Italian Learners of English. Retrieved (June, 15, 2016) from http://doria32-kk.lib.helsinki.fi/bitstream/handle/10024/98842/gradu_majuri_2014.pdf?sequence=2.

[15] Makkai, A., Boatner, M. T., \& Gates, J. E. (1995). A dictionary of American idioms (3rd ed.). Hauppauge, NY: Baron's Educational Series.

[16] Milosky, L. (1994). Nonliteral language abilities. In G. Wallach \& K. Butler (Eds.), Language learning disabilities in school-age children and adolescents (pp. 275-303). New York: Merrill.

[17] Nippold, M., \& Martin, S. (1989). Idiom interpretation in isolation versus context: A developmental study with adolescents. Journal of Speech and Hearing Research, 32/1, 59-66.

[18] Nippold, M. A. (1990). Idioms in textbooks for kindergarten through eighth grade students. Unpublished manuscript, University of Oregon, Eugene.

[19] Nippold, M. A., \& Rudzinski, M. (1993). Familiarity and transparency in idiom explanation: A developmental study of children and adolescents. Journal of Speech and Hearing Research, 36/4, 728-737.

[20] Nippold, M. A., \& Taylor, C. L. (1995). Idiom understanding in youth: Further examination of familiarity and transparency. Journal of Speech and Hearing Research, 38/2, 426-433.

[21] Nippold, M. A., \& Taylor, C. L. (2002). Judgments of idiom familiarity and transparency: A comparison of children and adolescents. Journal of Speech, Language, and Hearing Research, 45/2, 384-391.

[22] Norton, K.B. (1979). The effect of context on the understanding of idiomatic expressions and multiple meaning vocabulary words for monolingual and bilingual readers. Research paper prepared at the University of Miami.

[23] Ortony, A., Schallert, D. L., Reynolds, R. E., \& Antos, S. J. (1978). Interpreting metaphors and idioms: Some effects of context on comprehension. Journal of Verbal Learning and Verbal Behavior, 17, 464-477.

[24] Ortony, A., Turner, T. J., \& Larson-Shapiro, N. (1985). Cultural and instructional influences on figurative language comprehension by inner city children. Research in the Teaching of English, 19/1, 25-36.

[25] Pollio, H. R., J. M. Barlow, H. K. Fine \& M. R. Pollio. (1977). Psychology and the Poetics of Growth. Hillsdale, NJ : Erlbaum.

[26] Qualls, C. D., \& Harris, J. L. (1999). Effects of familiarity on idiom comprehension in African American and European American fifth graders. Language, Speech, and Hearing Services in Schools, 30/2, 141-151.

[27] Qualls, C. D., O’Brien, R. M., Blood, G. W., \& Hammer, C. S. (2003). Contextual variation, familiarity, academic literacy and rural adolescents' idiom knowledge. Language, Speech, and Hearing Services in Schools, 34/1, 69-79.

[28] Rohani, G., Ketabi, S., \& Tavakoli, M. (2012). The Effect of Context on the EFL Learners' Idiom Processing Strategies. English Language Teaching, 5(9), 104-114.

[29] Sameer S. Aljabri. (2013). EFL Students' Judgments of English Idiom Familiarity and Transparency. Journal of Language Teaching and Research, 4, 662-669.

[30] Tiv, M. (2016). Investigating the effects of transparency and ambiguity on idiom learning. Unpublished thesis, University of Pittsburgh. Retrieved (May 31, 2012) from http://d-scholarship.pitt.edu/27803/1/MTiv_Bphil_Final.pdf.

Hua Xie obtained her PhD in Applied Linguistics from Shanghai Jiaotong University. Currently she is a lecturer in the School of Foreign Languages, Shanghai University of Electric Power. Her main areas of research interest include second language acquisition, discourse analysis, academic English, EFL teaching. 